\title{
Contribution to the investigation of the Ti-Dy-Sn system
}

\author{
Yulia V. FARTUSHNA ${ }^{1 *}$, Andrej V. KOTKO ${ }^{1}$, Marina V. BULANOVA ${ }^{1}$ \\ ${ }^{1}$ I.N. Frantsevich Institute for Problems of Materials Science, \\ Krzhyzhanovsky St. 3, 03142 Kiev, Ukraine \\ * Corresponding author.Tel.: +380-044-4243090; e-mail: juliefart@mail.ru
}

Received June 15, 2009; accepted June 30, 2009; available on-line November 16, 2009

\begin{abstract}
A new ternary compound, $\mathrm{Ti}_{4.2-4.3} \mathrm{Dy}_{\mathbf{0 . 8 - 0 . 7} .7} \mathrm{Sn}_{\$ 3}(\tau)$, was found in the Ti-Dy-Sn system. It exists at an almost constant concentration of tin $(\sim 36.5$ at. \%), but has a certain homogeneity region $(8.2$ to 10.2 at.\% Dy) due to mutual substitution of titanium and dysprosium. The crystal system was determined to be hexagonal with preliminary lattice parameters $a=4.94 \AA, c=5.65 \AA$. The compound melts congruently above $1500^{\circ} \mathrm{C}$ and coexists with $\left(\mathrm{Ti}_{3} \mathrm{Sn}\right),\left(\mathrm{Dy}_{5} \mathrm{Sn}_{3}\right),\left(\mathrm{Ti}_{2} \mathrm{Sn}\right)$, and $\left(\mathrm{Ti}_{5} \mathrm{Sn}_{3}\right)$.
\end{abstract}

\section{Ternary compound / Crystal structure / Phase equilibrium}

\section{Introduction}

In the course of our investigation of phase equilibria in the Ti-Dy-Sn system, X-ray diffraction, microstructure and microprobe data indicated the formation of a ternary compound in the vicinity of 37.5 at.\% Sn. Literature data on the phase relations in the Ti-Dy-Sn system are absent. Our previous results $[1,2]$ do not involve the concentration mentioned above. Consequently, the ternary compound reported here appears to be a new one.

The aim of the present research was the examination of the crystal structure of the new compound, and the determination of its chemical composition.

\section{Experimental}

The purity of the starting materials was Ti-99.85\%, Dy-99.76\%, Sn-99.9995\%. The alloys were melted in an arc-furnace with an inconsumable tungsten electrode on a water-cooled copper hearth in an Ar atmosphere purified by a Ti-melt. To achieve homogeneity, the buttons were turned over and remelted three times. The weight losses did not exceed $0.3 \%$, so the composition of the samples was taken according to the initial mixture. The weight of the ingots was $\sim 5-10 \mathrm{~g}$.

The samples were studied, in as-cast and annealed states, by X-ray diffraction, light optical and electron scanning microscopy (LOM and SEM, respectively), transmission electron microscopy (TEM), differential thermal analysis (DTA) and electron microprobe analysis (EPMA). The conditions for the heat treatment are given in Table 1.
X-Ray diffraction was performed by the powder method in a Debye camera $(\mathrm{d}=57.3 \mathrm{~mm}$, URS-2.0 device) and from the cross section in a DRON-3.0 device, both equipped with filtered $\mathrm{Cu} \mathrm{K}_{\alpha}$ radiation. The lattice parameters were refined by the leastsquares method.

Examination of the microstructures and microprobe analysis were performed with a scanning electron microscope Jeol Superprobe-733 using backscattered electrons. This regime allowed us to identify the phases by their average atomic weight, where light-weight phases appear dark-colored and heavyweight phases light-colored [3].

DTA was performed in a VDTA-7-type device with a W/W-Re thermocouple in helium. The heating / cooling rate was $\sim 40-80^{\circ} \mathrm{C} / \mathrm{min} . \mathrm{Al}_{2} \mathrm{O}_{3}, \mathrm{ZrO}_{2}$ and $\mathrm{Sc}_{2} \mathrm{O}_{3}$ crucibles were used [4].

TEM examination was performed in a JEM100CXII device. A double-axis goniometer made it possible to tilt the sample $\pm 45^{\circ}$ along two mutually perpendicular axes. The samples used for the investigation were mechanically powdered, and fine particles were extracted. Each particle represented a single crystal.

\section{Results and discussion}

During our examination of the Ti-Dy-Sn system it appeared that the X-ray diffraction patterns and microstructure data for the alloys with 27.5 to 37.5 at. \% Sn could be interpreted only if the existence of a ternary compound was accepted. All the patterns contained a new system of reflections, which was more 
Table 1 Phase compositions of as-cast and annealed Ti-Dy-Sn alloys and microprobe analysis of the ternary compound $\tau$.

\begin{tabular}{|c|c|c|c|c|c|c|c|}
\hline \multicolumn{3}{|c|}{ Alloy, at.\% } & \multirow[t]{2}{*}{ Heat treatment } & \multirow[t]{2}{*}{ Phase composition } & \multicolumn{3}{|c|}{$\begin{array}{c}\text { Chemical composition of } \\
\tau, \text { at. } \%\end{array}$} \\
\hline $\mathrm{Ti}$ & Dy & $\mathrm{Sn}$ & & & $\mathrm{Ti}$ & Dy & $\mathrm{Sn}$ \\
\hline \multirow{3}{*}{65} & \multirow{3}{*}{5} & \multirow{3}{*}{30} & $\begin{array}{c}1100^{\circ} \mathrm{C}, 30 \mathrm{~h}+900^{\circ} \mathrm{C}, 32 \mathrm{~h}+ \\
1400^{\circ} \mathrm{C}, 30 \mathrm{~h}\end{array}$ & $\left(\mathrm{Ti}_{3} \mathrm{Sn}\right)+\tau$ & 54.55 & 9.08 & 36.37 \\
\hline & & & \multirow{2}{*}{$1100{ }^{\circ} \mathrm{C}, 30 \mathrm{~h}$} & \multirow{2}{*}{$\left(\mathrm{Ti}_{3} \mathrm{Sn}\right)+\tau$} & 53.29 & 8.61 & $38.10^{\mathrm{a}}$ \\
\hline & & & & & 53.92 & 8.30 & $37.79^{\mathrm{a}}$ \\
\hline \multirow{2}{*}{62.5} & \multirow{2}{*}{5} & \multirow{2}{*}{32.5} & \multirow{2}{*}{ as-cast } & \multirow{2}{*}{$\left(\mathrm{Ti}_{3} \mathrm{Sn}\right)+$ eutectic $\left(\left(\mathrm{Ti}_{3} \mathrm{Sn}\right)+\tau\right)$} & 55.03 & 9.87 & 36.00 \\
\hline & & & & & 54.92 & 8.49 & 36.59 \\
\hline \multirow{2}{*}{65} & \multirow{2}{*}{1.7} & \multirow{2}{*}{33.3} & \multirow{2}{*}{$1100^{\circ} \mathrm{C}, 30 \mathrm{~h}$} & \multirow{2}{*}{$\left(\mathrm{Ti}_{2} \mathrm{Sn}\right)+\tau+\left(\mathrm{Ti}_{3} \mathrm{Sn}\right)$} & 53.24 & 8.17 & $38.59^{\mathrm{a}}$ \\
\hline & & & & & 53.32 & 8.40 & $38.28^{\mathrm{a}}$ \\
\hline \multirow{3}{*}{63} & \multirow{3}{*}{2} & \multirow{3}{*}{35} & \multirow{3}{*}{$1400^{\circ} \mathrm{C}, 30 \mathrm{~h}$} & \multirow{3}{*}{$\left(\mathrm{Ti}_{2} \mathrm{Sn}\right)+\tau$} & 54.91 & 9.37 & 35.72 \\
\hline & & & & & 53.73 & 9.56 & 36.71 \\
\hline & & & & & 54.91 & 8.38 & 36.71 \\
\hline \multirow{5}{*}{57.5} & \multirow{5}{*}{7.5} & \multirow{5}{*}{35} & \multirow{3}{*}{ as-cast } & & 54.77 & 8.71 & 36.52 \\
\hline & & & & $\tau+$ eutectic $\left(\left(\mathrm{Ti}_{3} \mathrm{Sn}\right)+\tau\right)$ & 53.86 & 9.63 & 36.52 \\
\hline & & & & & 54.36 & 9.03 & 36.61 \\
\hline & & & & & 54.71 & 9.26 & 36.02 \\
\hline & & & $1400 \mathrm{C}, 30 \mathrm{n}$ & $\left(11_{3} S n\right)+\tau+\left(11_{2} S n\right)$ & 54.09 & 9.57 & 36.34 \\
\hline & & & & & 54.31 & 9.71 & 35.98 \\
\hline & & & as-cast & $\begin{array}{l}\tau+\left(\mathrm{Ti}_{3} \mathrm{Sn}\right)+\text { eutectic } \\
\left(\left(\mathrm{Ti}_{2} \mathrm{Sn}\right)+\left(\mathrm{DV}_{-} \mathrm{Sn}_{2}\right)\right)\end{array}$ & 54.43 & 9.28 & 36.30 \\
\hline & & & & & 53.45 & 10.03 & 36.52 \\
\hline 55 & 10 & 35 & & & 53.81 & 9.49 & 36.70 \\
\hline & & & & & 53.91 & 10.01 & 36.08 \\
\hline & & & $1400 \mathrm{C}, 30 \mathrm{n}$ & $\left(11_{3} \mathrm{Sn}\right)+\tau+\left(\mathrm{D} y_{5} \mathrm{Sn}_{3}\right)$ & 54.30 & 9.88 & 35.82 \\
\hline & & & & & 53.59 & 10.27 & 36.15 \\
\hline 52.5 & 12.5 & 35 & as-cast & $\begin{array}{c}\tau+\left(\mathrm{Ti}_{3} \mathrm{Sn}\right)+\text { eutectic } \\
\left(\left(\mathrm{Dy}_{5} \mathrm{Sn}_{3}\right)+?\right)\end{array}$ & 53.71 & 9.84 & 36.45 \\
\hline 60.5 & 2 & 37.5 & as-cast & $\tau+\left(\mathrm{Ti}_{2} \mathrm{Sn}\right)+\left(\mathrm{Ti}_{5} \mathrm{Sn}_{3}\right)$ & 54.72 & 9.25 & 36.04 \\
\hline 58.5 & 4 & 37.5 & as-cast & $\tau+\left(\mathrm{Ti}_{2} \mathrm{Sn}\right)+\left(\mathrm{Ti}_{5} \mathrm{Sn}_{3}\right)+?$ & 54.61 & 8.90 & 36.49 \\
\hline & & & & $\left(\mathrm{Ti}_{2} \mathrm{Sn}\right)+$ & 54.63 & 8.70 & 36.67 \\
\hline 56.5 & 6 & 37.5 & as-cast & $\tau+\left(\mathrm{Ti}_{5} \mathrm{Sn}_{3}\right)+?+$ eutectic & 55.30 & 8.56 & 36.15 \\
\hline & & & & $\left(\tau+\left(\mathrm{Ti}_{2} \mathrm{Sn}\right)\right)$ & 54.89 & 8.86 & 36.25 \\
\hline 54.5 & 8 & 37.5 & & & 54.16 & 9.39 & 36.45 \\
\hline 54.5 & $\delta$ & $3 / .5$ & as-cast & $\tau+\left(11_{5} \mathrm{Sn}_{3}\right)+!$ & 54.41 & 9.10 & 36.49 \\
\hline 525 & 10 & 375 & & & 53.20 & 10.41 & 36.39 \\
\hline SL.5 & 10 & 31.5 & as-cast & $\tau+!$ & 53.94 & 9.49 & 36.57 \\
\hline
\end{tabular}

${ }^{\mathrm{a}}$ The content of tin is overestimated.

evident in the alloys along the isoconcentrate $37.5 \mathrm{Sn}$. In the alloys $\mathrm{Ti}-(8-10) \mathrm{Dy}-37.5 \mathrm{Sn}$ the reflections of the boundary binary phases were absent. In contrast, in the alloys Ti-(2-6)Dy-37.5Sn additional reflections from $\mathrm{Ti}_{5} \mathrm{Sn}_{3}$ were well indexed, showing, thus, Dy solubility in $\mathrm{Ti}_{5} \mathrm{Sn}_{3}$ of less than $2 \%$. In the alloys Ti(10-15)Dy-(32.5-35)Sn the new reflection system was observed together with weak reflections of $\left(\mathrm{Ti}_{3} \mathrm{Sn}\right)$ and of $\left(\mathrm{Dy}_{5} \mathrm{Sn}_{3}\right)$, and in the alloys Ti-(2-5)Dy-(32.5-35)Sn it coexisted with weak reflections of $\left(\mathrm{Ti}_{3} \mathrm{Sn}\right)$ and with well indexed reflections of $\left(\mathrm{Ti}_{2} \mathrm{Sn}\right)$. The chemical compositions of the alloys containing the new reflection system are shown in the partial solidus surface and in the isothermal section at $1400^{\circ} \mathrm{C}$, Fig. 1. The phase compositions of the studied alloys are given in Table 1. A partial X-ray diffraction pattern of the as-cast 52.5Ti-10Dy-37.5Sn sample, containing only the new reflection system, is shown in Fig. 2. The almost single-phase microstructure of this sample, ascast and annealed at $1400^{\circ} \mathrm{C}$ for $30 \mathrm{~h}$, is shown in Fig. 3a,b. Attempts to index these reflections in the structure types $\mathrm{Mn}_{5} \mathrm{Si}_{3}, \mathrm{~W}_{5} \mathrm{Si}_{3}$ or $\mathrm{Cr}_{5} \mathrm{~B}_{3}$, typical for $5 / 3$ compositions, failed. These results led us to the conclusion that a new ternary compound $\tau$, containing about 37.5 at.\% Sn, exists and its chemical composition can be written as $(\mathrm{Ti}, \mathrm{Dy})_{5} \mathrm{Sn}_{3}$.

The single crystal particles extracted from the ascast alloys 54.5Ti-12.5Dy-35Sn and 52.5Ti-10Dy$37.5 \mathrm{Sn}$ were studied by electron diffraction to examine the crystal structure of the $\tau$ compound. A typical view of the studied particles is shown in Fig. 4. The crystals were tilted with the help of a goniometer 

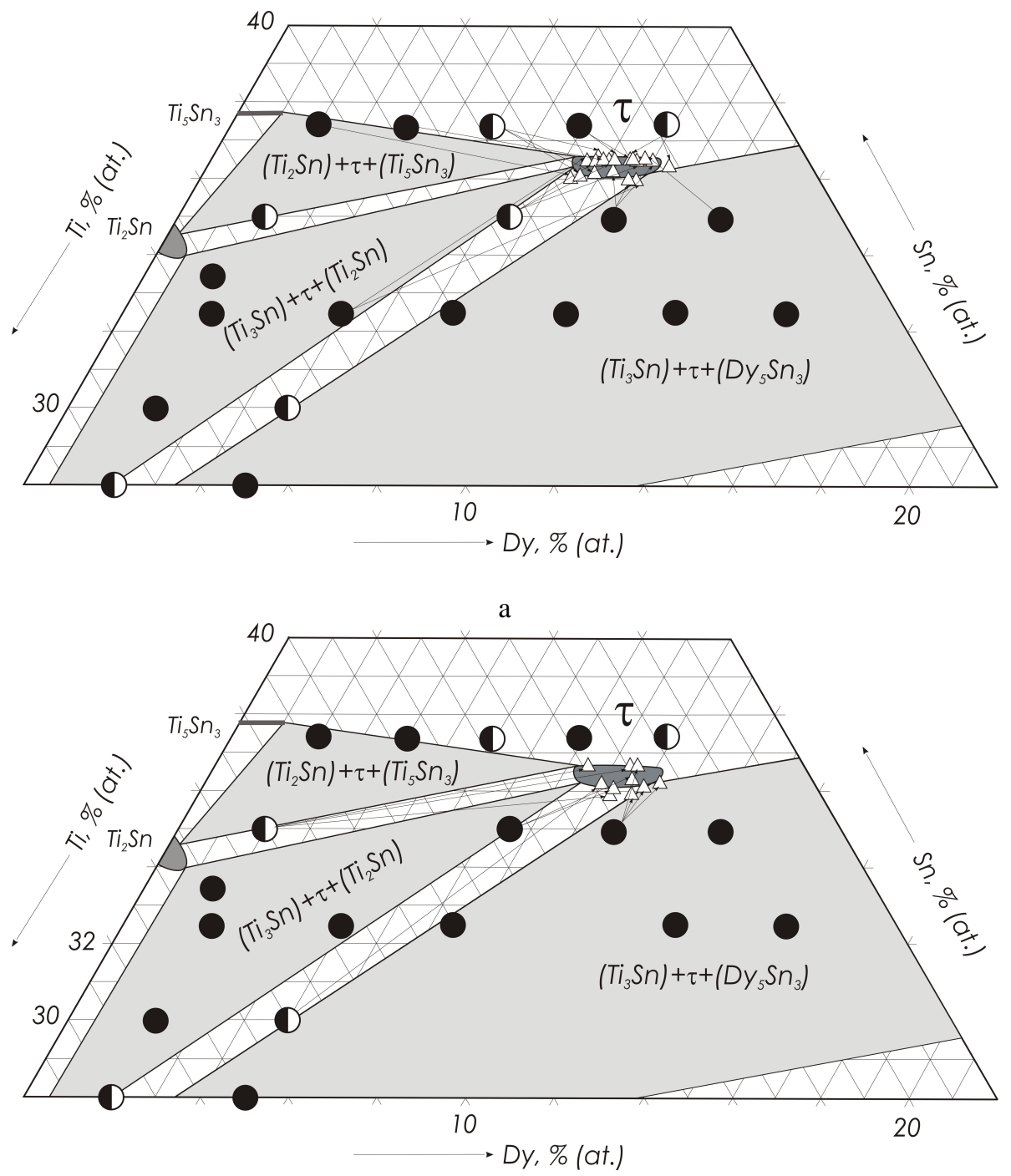

b

Fig. 1 Partial solidus surface (a) and isothermal section at $1400^{\circ} \mathrm{C}$ (b) of the Ti-Dy-Sn system in the vicinity of the ternary compound $\tau$ based on results of this work: $\mathbf{D}$ - two-phase sample, $\mathbf{0}-$ three-phase sample, $\Delta-$ EPMA data, the arrows indicate the composition of $\tau$ in the alloys.

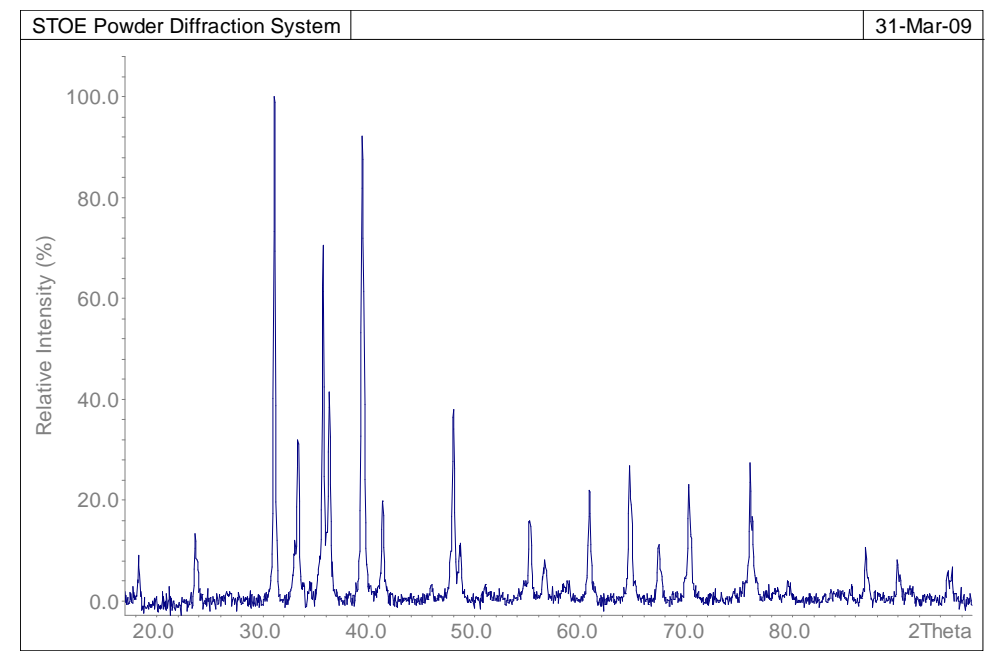

Fig. 2 Reflection system of the $\tau$ compound in a partial X-ray diffraction pattern of the as-cast 52.5Ti-10Dy37.5Sn alloy. 


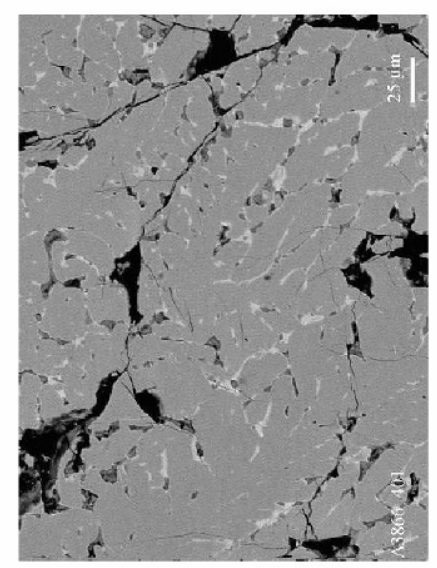

a
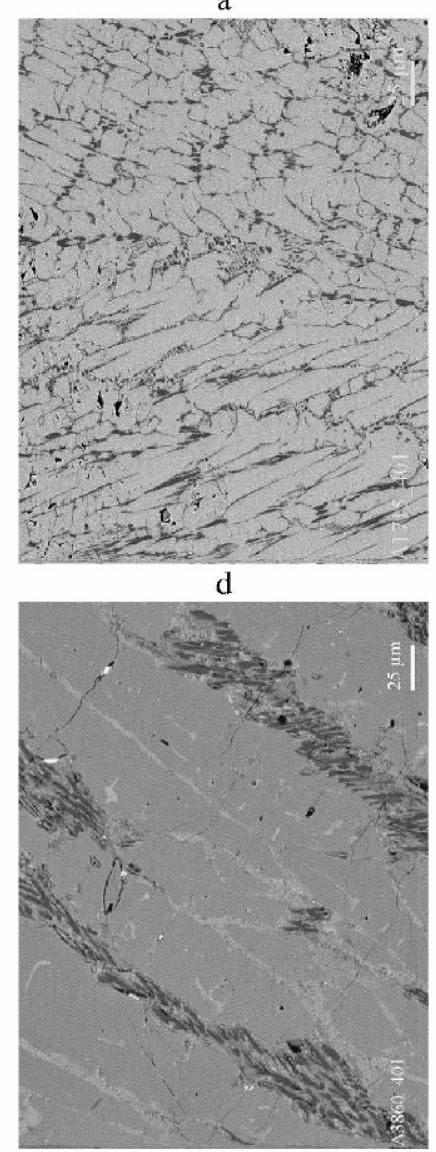

$\mathrm{g}$

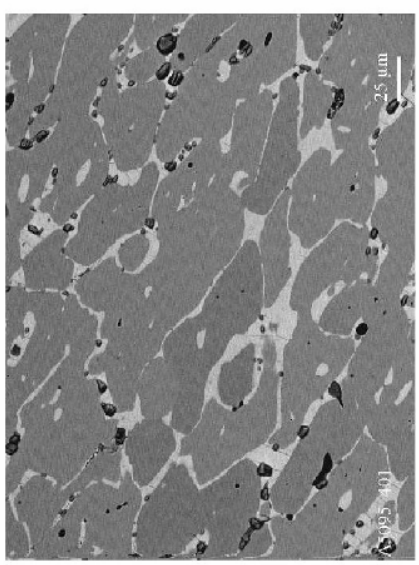

b
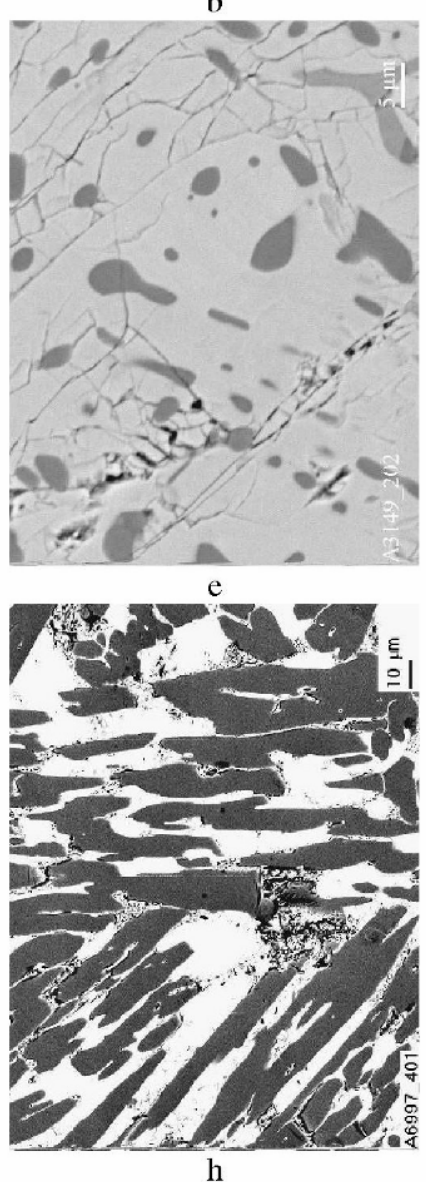

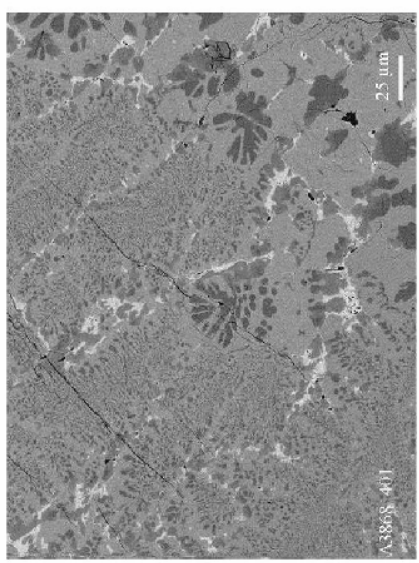

c

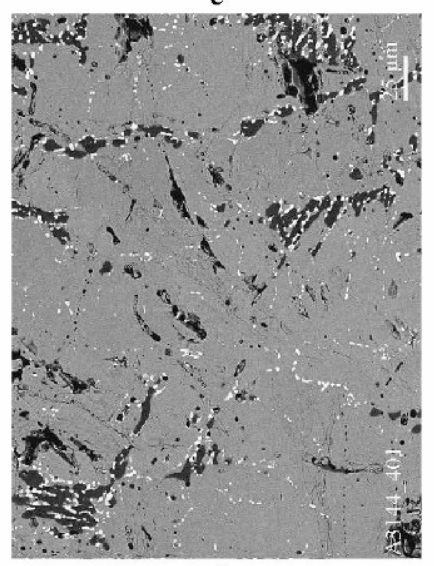

f

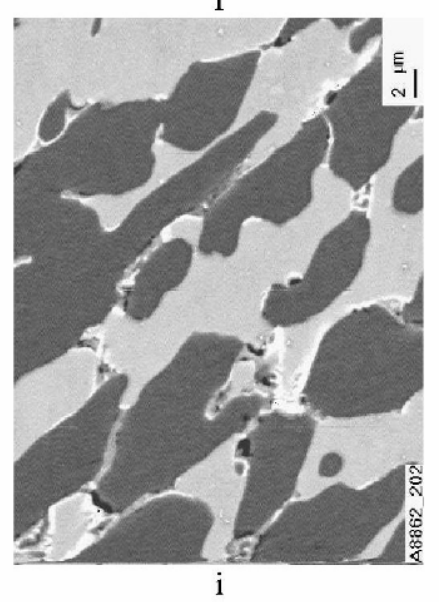

Fig. 3 Microstructure of Ti-Dy-Sn alloys: a) 52.5Ti-10Dy-37.5Sn, as-cast, $\times 400$, $\tau+$ ?; b) 52.5Ti-10Dy$37.5 \mathrm{Sn}, 1400^{\circ} \mathrm{C} 30 \mathrm{~h}, \times 400, \tau+$ ?; c) $56.5 \mathrm{Ti}-6 \mathrm{Dy}-37.5 \mathrm{Sn}$, as-cast, $\times 400,\left(\mathrm{Ti}_{2} \mathrm{Sn}\right)+\tau+\left(\mathrm{Ti}_{5} \mathrm{Sn}_{3}\right)+?+$ eutectic $\left(\left(\mathrm{Ti}_{2} \mathrm{Sn}\right)+\tau\right)$; d) $57.5 \mathrm{Ti}-7.5 \mathrm{Dy}-35 \mathrm{Sn}$, as-cast, $\times 400, \tau+$ eutectic $\left(\left(\mathrm{Ti}_{3} \mathrm{Sn}\right)+\tau\right)$; e) $57.5 \mathrm{Ti}-7.5 \mathrm{Dy}-35 \mathrm{Sn}, 1400^{\circ} \mathrm{C}$ $\left.\left.30 \mathrm{~h}, \times 2000, \tau+\left(\mathrm{Ti}_{3} \mathrm{Sn}\right)+\left(\mathrm{Ti}_{2} \mathrm{Sn}\right) ; \mathrm{f}\right) 55 \mathrm{Ti}-10 \mathrm{Dy}-35 \mathrm{Sn}, 1400^{\circ} \mathrm{C} 30 \mathrm{~h}, \times 400, \tau+\left(\mathrm{Ti}_{3} \mathrm{Sn}\right)+\left(\mathrm{Dy}_{5} \mathrm{Sn}_{3}\right) ; \mathrm{g}\right) 52.5 \mathrm{Ti}-$ 12.5Dy-35Sn, as-cast, $\times 400, \tau+\left(\mathrm{Ti}_{3} \mathrm{Sn}\right)+$ eutectic $\left.\left(\left(\mathrm{Dy}_{5} \mathrm{Sn}_{3}\right)+?\right) ; \mathrm{h}\right) 65 \mathrm{Ti}-5 \mathrm{Dy}-30 \mathrm{Sn}, 1100^{\circ} \mathrm{C} 30 \mathrm{~h}, \times 400$, $\tau+\left(\mathrm{Ti}_{3} \mathrm{Sn}\right)$; i) $65 \mathrm{Ti}-5 \mathrm{Dy}-30 \mathrm{Sn}, 1100^{\circ} \mathrm{C} 30 \mathrm{~h}+900^{\circ} \mathrm{C} 32 \mathrm{~h}, \times 2000, \tau+\left(\mathrm{Ti}_{3} \mathrm{Sn}\right)+\left(\mathrm{Dy}_{5} \mathrm{Sn}_{3}\right)$. 


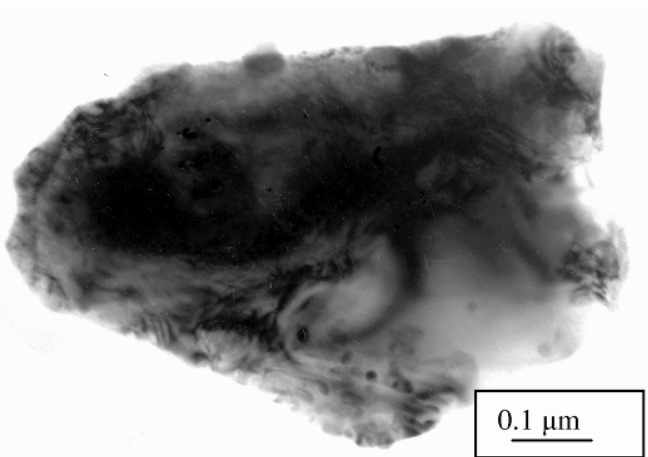

a

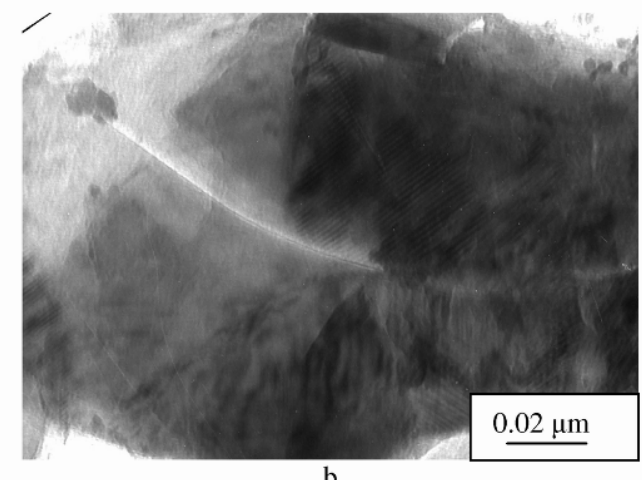

Fig. 4 Typical view of a particle extracted from the as-cast 52.5Ti-10Dy-37.5Sn alloy for TEM examinations: a) $\times 100000$, b) $\times 400000$.
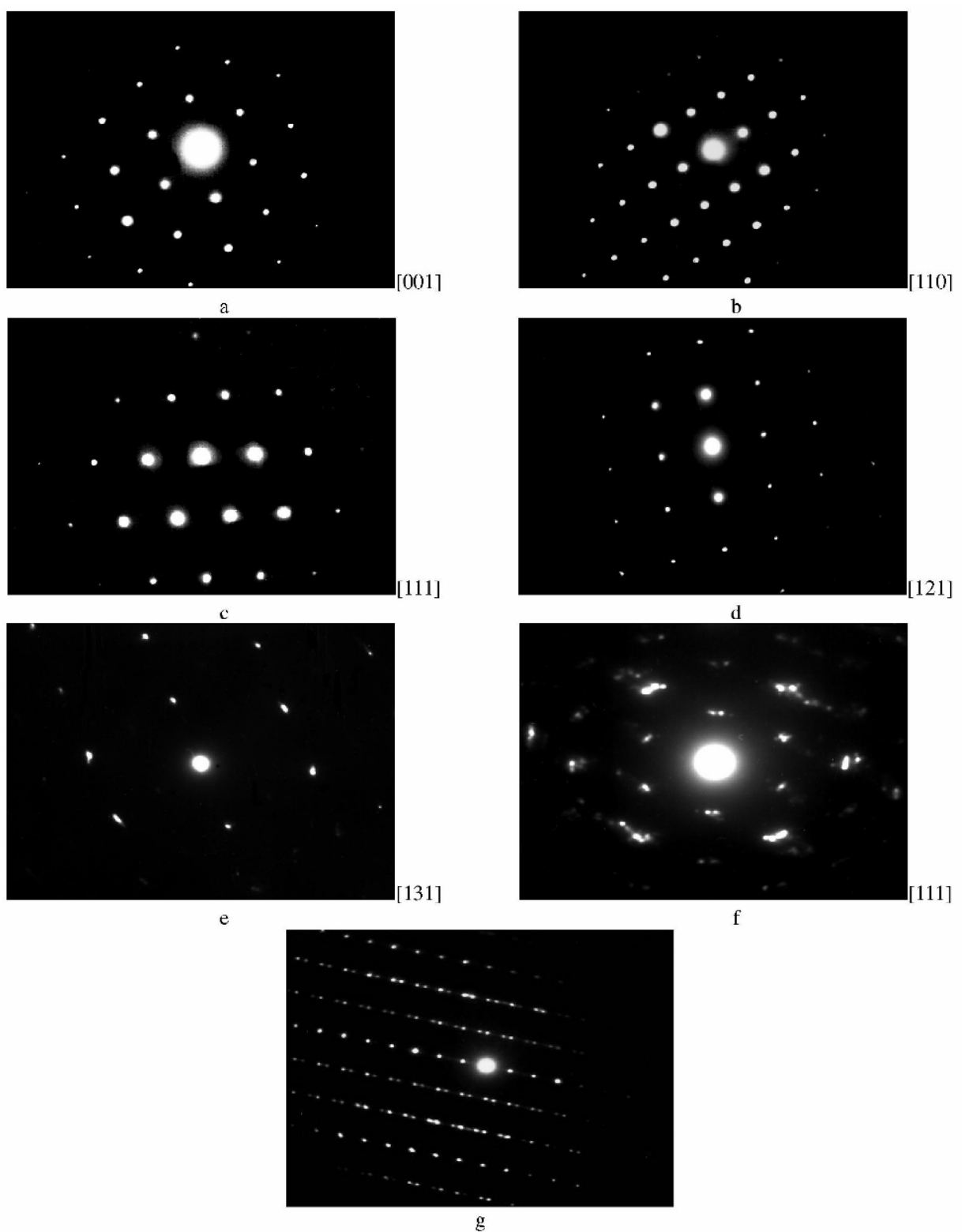

Fig. 5 Electron diffraction patterns in as-cast 52.5Ti-10Dy-37.5Sn sample from the atomic planes: a) (001), b) (110), c, f) (111), d) (121), e) (131), g) not determined. 
to obtain electron diffraction patterns from the planes with minimum deviation from the primary beam. Thus, a few electron diffraction patterns of different orientations were obtained from each extracted crystal, Fig. 5a-d. Analysis of the patterns allowed us to establish the hexagonal system for the $\tau$ compound. The lattice parameters were determined as $a=4.94 \AA$, $c=5.65 \AA$.

It should be noticed that most of the studied particles revealed a layer-like structure, resulted both in moiré fringes in the images, Fig. 4b, and in double reflections of electron diffraction, Fig. 5e, f. Some of the electron diffraction patterns show reflections corresponding to twin orientations of neighboring crystals. This makes us believe that the structure is probably more complex consisting of clusters. The lattice parameters determined here should thus be considered as preliminary and a more precise examination of the space group and determination of the atomic positions by X-ray diffraction is necessary. The crystal structure is under investigation at present.

The chemical composition of the new compound was determined by EPMA, the results are given in Table 1, and Fig. 1. A number of representative microstructures are shown in Fig. 3. At the solidus temperatures the ternary compound was found to contain 36.5 at. \% Sn, rather than 37.5 at.\% Sn, as we supposed previously. The compound has a homogeneity range, with limits corresponding to 8.2 and 10.2 at.\% Dy, formed by mutual substitution of $\mathrm{Ti}$ and Dy atoms. Consequently, the composition of the compound can be written as $\mathrm{Ti}_{4.2-4.3} \mathrm{Dy}_{0.8-0.7} \mathrm{Sn}_{\lessgtr 3}$. A decrease of the temperature down to $1400^{\circ} \mathrm{C}$ does not significantly change the width of the homogeneity range. The compound was observed also in alloys annealed at 1100 and $900^{\circ} \mathrm{C}$.

According to the results of the microstructure analysis, the compound melts congruently. The melting temperature determined by DTA is above $1500^{\circ} \mathrm{C}$. The $\tau$ compound is in equilibrium with $\left(\mathrm{Ti}_{3} \mathrm{Sn}\right),\left(\mathrm{Dy}_{5} \mathrm{Sn}_{3}\right),\left(\mathrm{Ti}_{2} \mathrm{Sn}\right)$, and $\left(\mathrm{Ti}_{5} \mathrm{Sn}_{3}\right)$, as shown in Fig. 1.

\section{Conclusions}

1. A new ternary compound $\tau\left(\mathrm{Ti}_{4.2-4.3} \mathrm{Dy}_{0.8-0.7} \mathrm{Sn}_{\lessgtr 3}\right)$ was found in the Ti-Dy-Sn system. The compound exists at an almost constant concentration of tin of about 36.5 at.\%, and has a homogeneity range along this isoconcentrate. The compound melts congruently above $1500^{\circ} \mathrm{C}$.

2. The hexagonal translation lattice of the $\tau$ compound was determined by the TEM method. The preliminary lattice parameters are: $a=4.94 \AA, c=$ $5.65 \AA$.

3. At the solidus temperatures and at $1400^{\circ} \mathrm{C}$ the $\tau$ compound was shown to be in equilibrium with $\left(\mathrm{Ti}_{3} \mathrm{Sn}\right),\left(\mathrm{Dy}_{5} \mathrm{Sn}_{3}\right),\left(\mathrm{Ti}_{2} \mathrm{Sn}\right)$, and $\left(\mathrm{Ti}_{5} \mathrm{Sn}_{3}\right)$.

\section{References}

[1] M.V. Bulanova, Yu.N. Podrezov, Yu.V. Fartushnaya, R.A. Danilyuk, K.A. Meleshevich, Teor. Prakt. Metallurg. 4-5 (2006) 4-6.

[2] M.V. Bulanova, Yu.N. Podrezov, Yu.V. Fartushnaya, A.N. Rafal, S.A. Firstov. Dopov. Nats. Akad. Nauk Ukr. 6 (2007) 95-104.

[3] E.V. Panchenko, Yu.A. Skakov, B.I. Krimer, P.P. Arsentiev, K.V. Popov, M.Ya. Tsviling. Laboratoriya Metallografii, Metallurgia, Moscow, 1965, 439 p.

[4] Yu.A. Kocherjinsky, N.A. Bezshtan'ko, V.I. Vasilenko, Izv. Sib. Otd. Akad. Nauk SSSR, Ser. Khim. Nauk 4(9) (1974) 32-35. 